\title{
Research on Nature and Development Trend of Legal Digital Currency
}

\author{
Wei Jun \\ (College of Marxism, Minnan Normal University, Zhangzhou 363000, China)
}

\begin{abstract}
From the perspective of Marxist monetary theory, legal digital money absorbs the advantages of blockchain technology, cryptography technology, and computer technology of virtual money, overcomes its shortcomings, and carries out a complete top-level design, which is visionary and scientific. With the introduction of virtualization and digitalization into the currency field by electronic information technology, the traditional form of money has changed, and many kinds of virtual money forms, such as Bitcoin, emerge endlessly. To gradually adapt to the new state of currency and effectively overcome the shortcomings of the international monetary system, it is imperative to innovate the statutory digital currency.
\end{abstract}

keywords : statutory digital currency; top-level design; the international monetary system

DOI : $10.36012 /$ fhe. v2i3. 2777

he subprime mortgage crisis of the $\mathbf{T}$ United States and the hegemony of the United States dollar have resulted in adverse consequences, making the virtual currency emerge at the right time and grow with the times, spreading rapidly and affecting the international monetary and financial system. To excavate the essence of virtual currency, to study its reasonable and legitimate form of existence, and to maintain the stability of the international monetary system are the problems we need to study and find solutions to them.

\section{The Nature and Defects of Virtual Money}

At the macro- level, the reasons for Bitcoin's entry into the market are as follows: firstly, as a set- tlement or reserve currency, Bitcoin can avoid the inflation caused by the excessive issuance of the US dollar, and to a certain extent, curb the hegemony of the US dollar in the world; secondly, its payment principle can get rid of the issuance of the international reserve currency in the currency circulation link. The bank's control over other countries; finally, its direct voting rights in the relations of issuance, anti-aggression, trading rules, and client perfection enhance its stability, which can effectively solve the problems of sharp exchange rate fluctuations, credit risks, and bank risks in the monetary system under the control of the United States and Europe. At the micro-level, the emergence of virtual currencies such as Bit- 
coin benefit from the technical support provided by the Internet and blockchains. With computers and networks, we can participate in the manufacture and circulation of P2P networks. It is obvious that the high - speed and low - speed of P2P networks are apparent to all. The blockchain, as a database system, is characterized by a relatively complete structure, in - line information, relatively independent nodes, Byzantine tolerance, multi-independent nodes involved, a distributed system, and the underlying technology of digital currency.

The adverse impact of the dollar hegemony makes Bitcoin grow with the times, but its advantages are also its drawbacks: first, Bitcoin has a total design limitation, which is difficult to modify, which is not compatible with the scale of today 's world economic development. Secondly, the use of distributed bookkeeping in Bitcoin is also a drawback because as the volume of transactions increases, the amount of information in blockchains will increase dramatically. The system load is currently beyond the capacity of technology such as Bitcoin. Once the system collapses, it will be a devastating impact. Finally, anonymity is a factor in Bitcoin's rapid growth, but it's also a drawback. Because of anonymity, Bitcoin holders don't need to prove that I can generate many accounts to deposit, receive and transfer Bitcoin. This address can not correspond to the real identity of the holder behind the speech. Trading can only be confirmed by miners on the blockchain. Trading is difficult to monitor and track. It is difficult for countries and governments that maintain the stability and fairness of the monetary system to recognize its legitimacy. The advantage of decentralization is that it exists relative to the international monetary market. Still, if the scope is narrowed to a country, it does not need such decentralization but requires government supervision. The elimination of regulation may become a means of money laundering and drug trafficking by criminals, leading to economic bubbles.

\section{The Essence of Legal Digital Currency}

The measures taken by China in dealing with the problem of virtual currency such as Bitcoin are visionary and scientific.

Why are they visionary? According to the strengths and weaknesses of Bitcoin and the problems that the US dollar brings to the world monetary system, the People's Bank of China has put forward another path, that is, legal digital currency. Although it has not yet been officially released, the systematic top - level technical design has been carried out, and research and testing are being accelerated. The legal digital currency to be issued by the central bank is inspired by the technological advantages of the virtual currency, such as Bitcoin's generation path, password characteristics, the blockchain concept, and electronic payment. It overcomes the shortcomings of unregulated, small-scale, and accounting technology and is guaranteed and issued by the central bank. Yao Qian believed that "in the future, the mainstream currencies of human society will have the characteristics of digital currency, electronic currency and global currency" and "the future world currency will certainly be a globally consistent digital currency system".

Why are they scientific? Firstly, from the theoretical basis of statutory digital currency, there are two forms of digital currency. One is based on accounts, and the other is based on wallets. They are two different concepts, and each has its advocates. For example, Ben Broadbent, deputy gover- 
nor of the Bank of England, agrees with the concept of wallets as accounts. Electronic wallets are like safekeeping boxes. Commercial banks may not have the right to open them, but they are on the client - side. Zhou Xiaochuan believes that the technical route of digital money to be issued by the central bank can be divided into two types : account - based and non - account-based, and can also be stratified and used to coexist. When the People's Bank of China enters into digital currency, it constructs two models: one is that the central bank directly faces users, the other is that it retains the dual structure of commercial banks. The latter, similar to RSCoin in the UK, is the ultimate and by far the best choice. Secondly, from the technical characteristics of legal digital currency, the technical support of legal digital currency and virtual currency such as Bitcoin at the basic level comes from blockchain technology, cryptography, and computer technology. Still, there are apparent differences between them. One of the advantages of Bitcoin is decentralization, but that's why it can't get its legal status. Because there is no supervision, there have been many cases of illegal elements used. The statutory digital currency is not de-centralized. It is supervised and controlled by the state and the government. It is centralized and has statutory monetary status. Bitcoin has no unified issuer, and any user can become a miner, maintaining stability through the computer system. If the individual user has a $51 \%$ computing speed of the network, then double payment can be realized through computer technology, the transaction will be reversed, the transfer function will be lost, and the whole network will be paralyzed. The statutory digital currency has an issuer, which controls the quantity and scale of issuance accord- ing to the specific conditions of economic and social development. It is endorsed by the state and government credit. For the digital currency controlled by the central bank, it will pass rigorous and thorough testing, use technical means according to laws and regulations so that the operating system of digital currency has a security guarantee. Zhou Xiaochuan believes that "digital currency can be based on the blockchain and Distributed Accounting technology, or it can be evolved based on existing electronic payment technology. There is a preliminary classification of the technical routes of digital money globally, and there are many possible systems. Finally, from the function of the statutory digital currency, the statutory digital currency to be issued by the central bank is the densified digitized RMB. In essence, it can be said to be the digitization of banknotes, and it is another form of currency with the same function as banknotes. According to the Marxist monetary theory, legal digital money, like paper money, has five functions and is still a general equivalent in essence. However, compared with paper money, digital money can save costs in the circulation and distribution links, improve the efficiency and security of transactions, and enhance the convenience of transactions. The statutory digital currency issued by the central bank does not conflict much with the current monetary system. The control of the issuing right of money makes it difficult for many countries to accept a unified new currency form. Bitcoin and other currencies are bound to be restricted, but there is no need to oppose the digital currency issued by the central bank.

\section{Future Development of Legal Digital Cur- rencies}

From the perspective of Marxist monetary theory, 
the reason for the emergence of different forms of money is to adapt to varying stages of social production. Marx thought: "One form of money may eliminate the insurmountable shortcomings of another form of money; however, as long as they are still monetary forms and as long as money is still an important production relationship, no form of money can eliminate the inherent contradictions of monetary relations, but only in one form or another. These contradictions are typically represented. The development and evolution of money form, whether it is paper money instead of metal money, or future digital money or other money forms instead of paper money, are all to deal with the problems in current economic and social life. It is a historical mission that needs to be solved and completed in the course of the development of money itself, and it is the issuance of money. According to exhibitions, they were normal phenomena in history. The new monetary form is also a process of negation and denial. It needs to be perfected and revised in practice, then tested and perfected in practice. Only in this way can we find a new currency to overcome the defects of the current world monetary system. Just as the emergence of Bitcoin contributed to the replacement of paper money, but not necessarily being Bitcoin, the legal digital currency was born on the basis of the technical advantages of Bitcoin. Still, future development may not be able to perform the function of world currency. In recent years, central banks have been actively promoting the construction of national statutory digital currency. Zhou Xiaochuan believed that "digital money has its inevitability of develop- ment, and paper money, coins will gradually shrink, even one day, will not exist. In developing a digital currency, we should pay attention to the stability of the whole financial system and protect consumers. China should carefully develop a digital currency, and research and development of digital currency should be promoted before thorough and local tests and after making sure that it is reliable. At present, because of the impact of the trade war initiated by the United States on China on economic activities, the supply chain has spread to the global scope, resulting in a significant slowdown in the global economy. Capital markets and monetary authorities across the world are urgently deploying responses. The dollar's drawbacks must be effectively eradicated. From the healthy development of the international monetary system, the statutory digital currency to be issued by the central bank is an Internet financial innovation worth looking forward.

\section{References}

[1] Wei Jun. Research on the importance of monetary work to the political development of the Western $\mathrm{Hu}^{-}$ nan and Hubei base areas. Economics and Management Science. Volume 1, Issue 1, 2020(12).

[2] Zhou Xiaochuan. Reflections on Reforming the International Monetary System. China Finance, No. 7,2009 .

[3] Yao Qian and Tang Yingwei. Some Thoughts on the Legal Digital Currency of the Central Bank. Financial Research, No. 7, 2017.

[4] Wei Jun. Research on the silver in the world flowing into Qing Dynasty. Economics and Management Science. Volume 1, Issue 1, 2019(09). 